\title{
UMA ANÁLISE DO MÉTODO CODESIGN, APLICADO EM GRUPOS DISTINTOS, PARA A IDENTIFICAČ̃̃O DE ELEMENTOS SIMBÓLICOS DO GUERREIRO ALAGOANO, NA CONFIGURAÇÃO DE ARTEFATOS.
}

\author{
Rayanna Alves Oliveira Eris
}

\begin{abstract}
Resumo: 0 presente resumo expandido, trata-se de uma abordagem do método codesign através de uma análise dos resultados obtidos entre dois grupos distintos (designers e não designers), visando identificar os elementos simbólicos do folguedo Guerreiro Alagoano para a transposição em design de produto. O codesign, foi uma das etapas do trabalho de conclusão de curso da autora para o desenvolvimento de uma coleção de joias inspiradas nos aspectos simbólicos do Guerreiro Alagoano. A utilização desta ferramenta multidisciplinar, possibilitou extrair de maneira não convencional, a averiguação dos aspectos simbólicos identificados por pesquisa bibliográfica e de campo. A análise comparativa dos resultados entre os dois processos realizados, foi imprescindível para a compreensão e identificação dos elementos mais reincidentes e característicos, possibilitando a aplicação dos mesmos em design de produto. Este processo, permitiu ao trabalho uma identificação mais precisa dos aspectos essenciais desse festejo, e com isso, uma melhor escolha dos simbolismos que possam ser utilizados no campo do design com o tema do folguedo em questão.
\end{abstract}

Palavras-chave: Codesign, Guerreiro Alagoano, Design de produto e Elementos simbólicos.

\section{INTRODUC̣ÃO}

O seguinte resumo, é uma análise dos resultados obtidos de uma etapa do trabalho de conclusão de curso da autora, que utilizou o método de Codesign no processo de desenvolvimento de design de produto. O método codesign, foi incorporado juntamente ao trabalho a metodologia de Löbach (2011), afim de averiguar os dados obtidos por pesquisa bibliográfica e de campo sobre o Guerreiro Alagoano. No processo, foram identificados e analisados os aspectos simbólicos que públicos distintos (designers e não designers) têm em relação ao Guerreiro, permitindo assim, uma escolha mais segura e precisa dos elementos simbológicos mais representativos do folguedo para a aplicação em design de produto.

O Guerreiro, é um folguedo natalino típico do estado, conforme Brandão (1953), surgiu em Alagoas na década de 20 em Viçosa. Trata-se de uma homenagem ao nascimento do Messias e aos três Reis Magos através do sincretismo religioso, é festejado e comemorado entre os dias 24 de dezembro, dia de Natal, até 6 de janeiro, dia de Reis. O Guerreiro, é um folguedo provindo do festejo religioso Reisado, que foi trazido pela colonização portuguesa, esta manifestação está presente em grande parte do território brasileiro. Assim como o Guerreiro, o Reisado também é uma comemoração natalina 
que sai nas ruas no dia de Reis os homenageando e anunciando a volta do Messias, em outras partes do país, esse festejo é conhecido também como Folia. Em alagoas, ainda segundo Brandão (1953), o Reisado se apropriou de influências culturais e festejos afros e indígenas, que acabaram influenciando o reisado da região e dando origem ao Guerreiro, o autor descreve este folguedo como um Auto peculiar, primo e alter ego do Reisado, por trazer consigo aspectos únicos em relação aos outros Reisados comemorados em outras partes do território brasileiro, em decorrência dessas influências, foram incorporados novos elementos diferenciados, como por exemplo: os variados entremeios, os personagens místicos, os diferentes chapéus e a introdução de elementos e personagens afros e indígenas, (DA SILVA, 2016).

O estado de Alagoas, apresenta um cenário cultural muito vasto e multi referencial herdado pelas influências de distintas culturas, sendo as mais influentes a cultura indígena, europeia e afrodescendente. A abundante diversidade desta herança heterogênea, contribuiu para o florescimento de um número considerável de manifestações culturais. De acordo com IPHAN (2008), são catalogadas mais de trinta manifestações no estado, dentre essas manifestações destaca-se o Guerreiro, um folguedo genuinamente do estado, patrimônio cultural e imaterial de Alagoas.

Nos dias atuais, a sociedade se encontra em um grande dilema, e preocupação em manter viva suas tradições folclóricas em um mundo voltado para a modernidade, apesar de que a descaracterização e reinvenção das manifestações folclóricas ao decorrer dos tempos fazer parte da evolução do próprio folclore, De Lima (2003). No entanto, para continuarem vivas e mantidas na memória, é necessário que haja a incorporação destas manifestações no dia a dia da população, para que assim, sejam motivadas, reconhecidas e enaltecidas, promovendo o fortalecimento das mesmas, como símbolos da identidade cultural, em conjunto com o reconhecimento da população, (AGUINAGA, 2007).

O Auto Natalino Guerreiro, é considerado um ícone Alagoano segundo a obra Iconografia Alagoana (2011), esta obra tem como finalidade, promover os ícones através de painéis imagéticos (figura 1), para a incorporação da regionalidade do estado e o fornecimento deste material para empreendedores utilizarem como diferencial competitivo em seus produtos. 0 design tem como objetivo atribuir tarefas multifacetadas aos objetos, proporcionar benefícios à sociedade, como também, promover a diversidade cultural apesar da globalização, assim como proporcionar a troca econômica e cultural, (SCOLARI 2008 apud ICSID 2008).

Figura 1 - Páginas 128 e 129 retiradas do livro Iconografia Alagoana Fonte: LÊDO, Ricardo, Guerreiro, 2011.

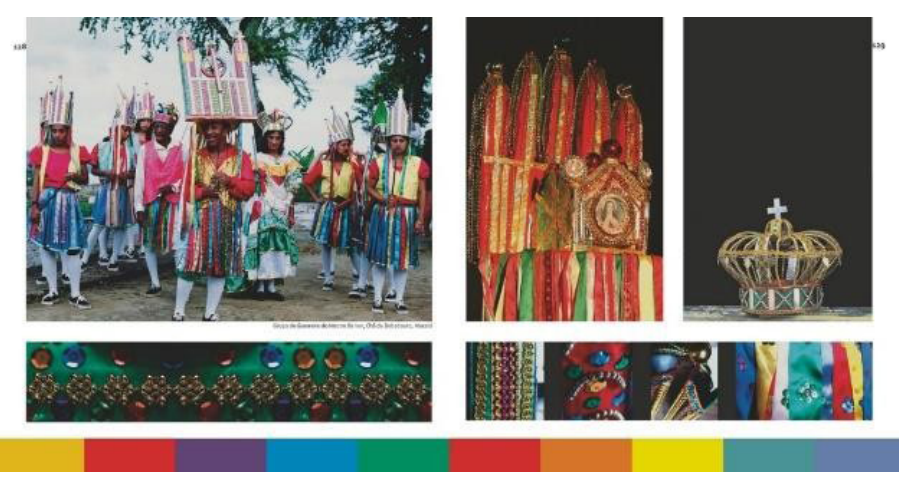

Portanto, com o intuito de valorizar este folguedo, e trazer esta manifestação mais próxima da população, o design pode através da incorporação da função estética simbólica no produto ser um transmissor de uma mensagem estética. Segundo Löbach (2011), quando há aspectos intelectuais e emocionais na percepção do produto, passam a ser compreendidos pelos usuários através da comunicação estética, neste caso, o designer industrial é o emissor de uma mensagem em forma de um produto industrial. 
Portanto, buscou-se analisar os resultados obtidos nos procedimentos, realizados de mesma forma em cada grupo (designers e não designers), e por meio dos resultados mais reincidentes, avaliar os elementos simbólicos deste festejo em cores, texturas, formas e expressões para a configuração de artefatos com este tema.

\section{METODOLOGIA E REFERENCIAL TEÓRICO}

Como guia projetual do trabalho no processo de desenvolvimento de produto, foi adotada a metodologia de Löbach (2001), que fornece bases projetuais para a configuração de produtos industriais, esta metodologia permite ao trabalho uma ampla abrangência de fatores que envolvem o produto, por meio de análises que favorecem o processo criativo, englobando funções práticas, estéticas e simbólicas. O trabalho, se iniciou através de coleta de dados feitas por meio de pesquisa de campo e pesquisa bibliográfica, entrevistas aos grupos de guerreiro e à estudiosos do tema da capital Maceió (vide anexo). Durante o processo metodológico, foi necessária a incorporação juntamente à metodologia adotada, o processo de Codesign, onde foram validados os aspectos simbólicos identificados em pesquisa bibliográfica e de campo. Para isso, foi determinado ter como parâmetro comparativo a percepção do folguedo entre públicos distintos, sendo um grupo formado por designers e outro formado por não designers, permitindo assim, uma visão mais segura da representatividade simbológica do guerreiro, como também, possibilita uma melhor aceitação da transposição dos elementos nos artefatos.

O codesign é um processo colaborativo, no qual várias pessoas em uma equipe multidisciplinar, colaboram no processo projetual de desenvolvimento de um produto, com o objetivo de chegar a um consenso e solução do problema de design. Este método, atualmente, vem sendo abordado constantemente em estudos e pesquisas, visto que, as tarefas projetuais estão se tornando cada vez mais complexas, como também, as tecnologias e sistemas buscam o melhor retorno ao mercado, sendo necessária a formação de equipes multidisciplinares, para que assim, seja possível a execução do processo de desenvolvimento do produto de design, (FONTANA, 2010). A cocriação é uma prática coletiva de criatividade, em que é experimentado e realizado por um grupo de pessoas coletivamente, sendo coordenadas por um moderador. Trata-se de um processo em que os participantes ficam num mesmo nível hierárquico e responsáveis pelo envolvimento com o trabalho a ser projetado sob a perspectiva do design. O processo de cocriação no design possibilita que as pessoas mostrem habilidade de criar e fornecer soluções para os projetos, desde que seu processo seja facilitado e que sejam guiadas para este fim, (KRUCKEN; MOL, 2014).

\section{PROCEDIMENTO DE CODESIGN}

Como já mencionado, o procedimento de Codesign teve como finalidade a averiguação dos dados obtidos por informações bibliográficas e de pesquisa de campo, para a identificação dos elementos simbólicos do Guerreiro alagoano na composição configuracional de design.

O processo foi realizado por meio de abordagens indiretas em dois momentos com grupos distintos, através de atividades padronizadas para ambos, um grupo foi composto por colaboradores não designers e outro por colaboradores designers formados e em formação no Curso de Design da Universidade federal de Alagoas. No procedimento, procurou-se realizar atividades nas quais o colaborador se sentisse à vontade em expressar em relação ao Guerreiro. Os resultados dos procedimentos serão comparados, 
e posteriormente analisados ao decorrer das etapas dos procedimentos que serão descritas respectivamente ao longo desta análise.

Inicialmente, para a preparação dos procedimentos, foram planejadas atividades que poderiam ser realizadas e os materiais que seriam utilizados para a atividade de criatividade, em que os colaboradores pudessem se expressar em forma de desenho, então foram estabelecidos os materiais para compor o Kit de criação, que foram escolhidos de acordo com o estudo de materiais mais utilizados, descritos por Maria Helena da Silva1, Anadeje Morais da Silva2 e André Joaquim dos Santos3 nas entrevistas com os grupos de Guerreiro, e também através da entrevista concedida pela museóloga Carmem Lúcia Dantas4, como também o painel do livro Iconografia Alagoana(2011), descrito anteriormente neste resumo (Vide p. 3). O kit de criação (Figura 2), foi composto por uma adaptação dos materiais mais utilizados nos chapéus e nos figurinos do Guerreiro, como por exemplo: glitter prateado, a fim de simbolizar os espelhos, fitas coloridas com as cores e tecidos utilizados, lantejoulas coloridas nas cores utilizadas, e papéis laminados do material da sacola que também poderiam ser utilizados e que representa também os materiais utilizados no Guerreiro. Para este processo criativo também foram disponibilizados outros materiais: como lápis, lápis de cor, cola, tesoura, fita adesiva, papel e borracha (Figura 3). A atividade utilizando estes materiais será descrita na $5^{\mathrm{a}}$ etapa do procedimento.

Figura 2 - Codesign para não designers. Fonte: Acervo da a pesquisa, 2017. Figura 3 - Codesign para designers Fonte: Acervo da autora, 2017.
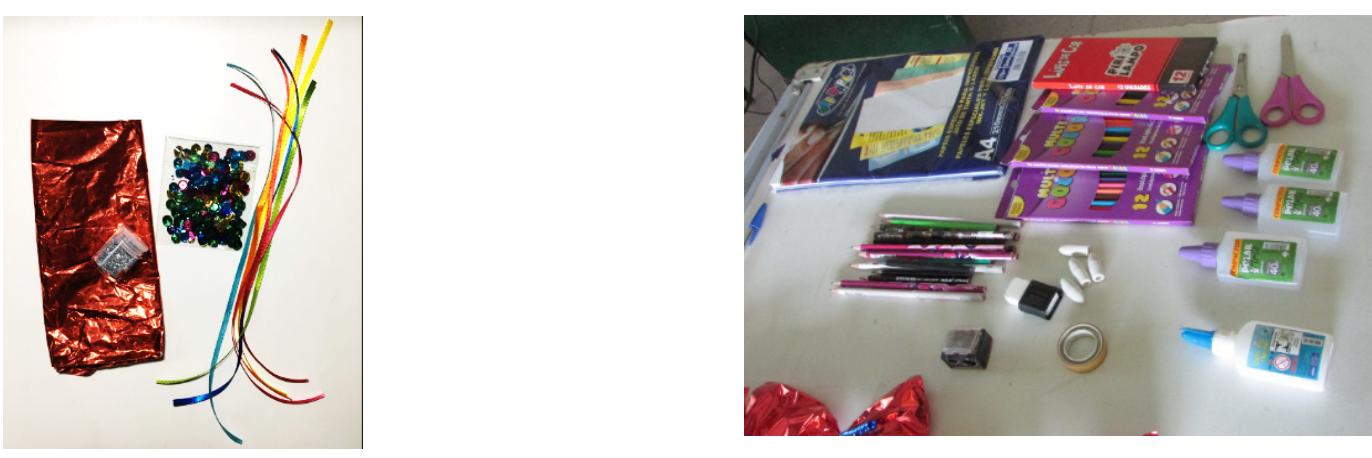

Em seguida, com o objetivo de identificar palavras ou expressões representativas do guerreiro, foram selecionadas palavras chave resultantes da pesquisa na coleta de dados, colhidas em pesquisa bibliográfica e de campo. As palavras chave selecionadas (Figura 4), representavam indiretamente as informações que se pretendia obter, de forma que os integrantes pudessem incorporar mais significações em relação ao tema, como por exemplo, ouvir a palavra "cores" implica em pensar em uma cor. Então, foram escritas palavras chave em um papel, objetivando constatar as palavras mais utilizadas em ambos os grupos na atividade, da 3a etapa que será descrita a diante. 


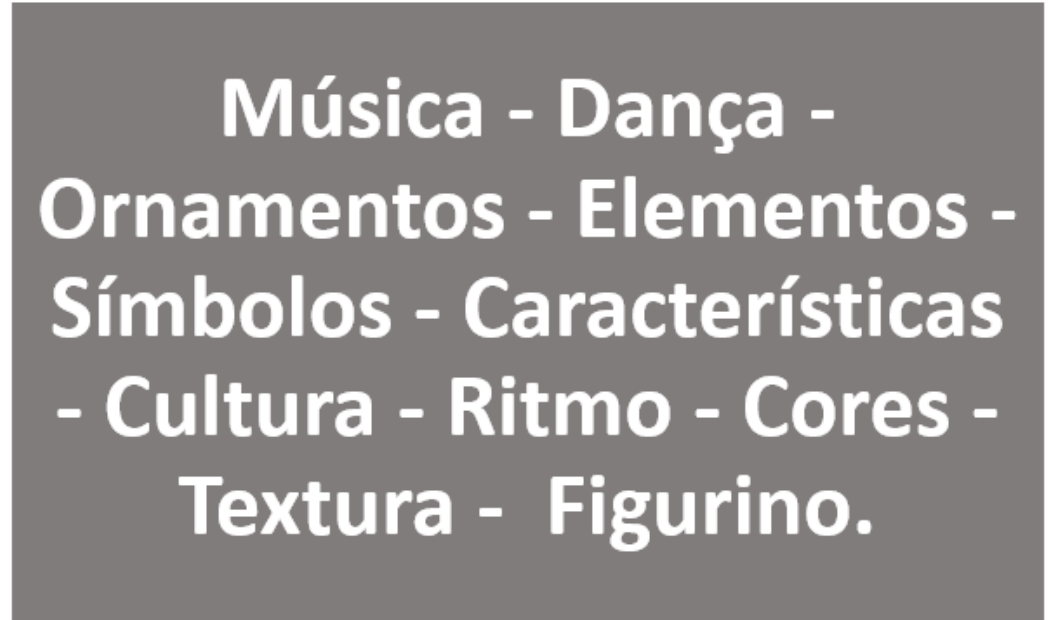

Posteriormente, foram selecionadas algumas imagens e um vídeo sobre o guerreiro, para utilizar também como material das atividades do procedimento. Para isto, foram escolhidas imagens contrastantes do Guerreiro, como por exemplo, uma criança e um idoso vestidos com o figurino de Guerreiro (Figura 5 e 6). Também foi escolhido um vídeo ${ }^{4}$, que apresenta o folguedo de uma forma bem interessante e artística, passando um sentimento de curiosidade sobre o folguedo para quem o assiste, com passagens de vários cenários, parte de falas de folcloristas, museólogos e participantes do Guerreiro, intervaladas com cenas de apresentações. A intenção da escolha, tanto das imagens quanto do vídeo foi deixar no imaginário dos colaboradores um pouco do universo do Guerreiro, a forma da utilização desses materiais será descrita nas etapas a seguir do procedimento.

Figura 5 - Criança de Guerreiro. Fonte: BRANCO, Lula Castello, 2016. Figura 6 - Idoso de Guerreiro. Fonte: LINS, Jonathan, 2015.
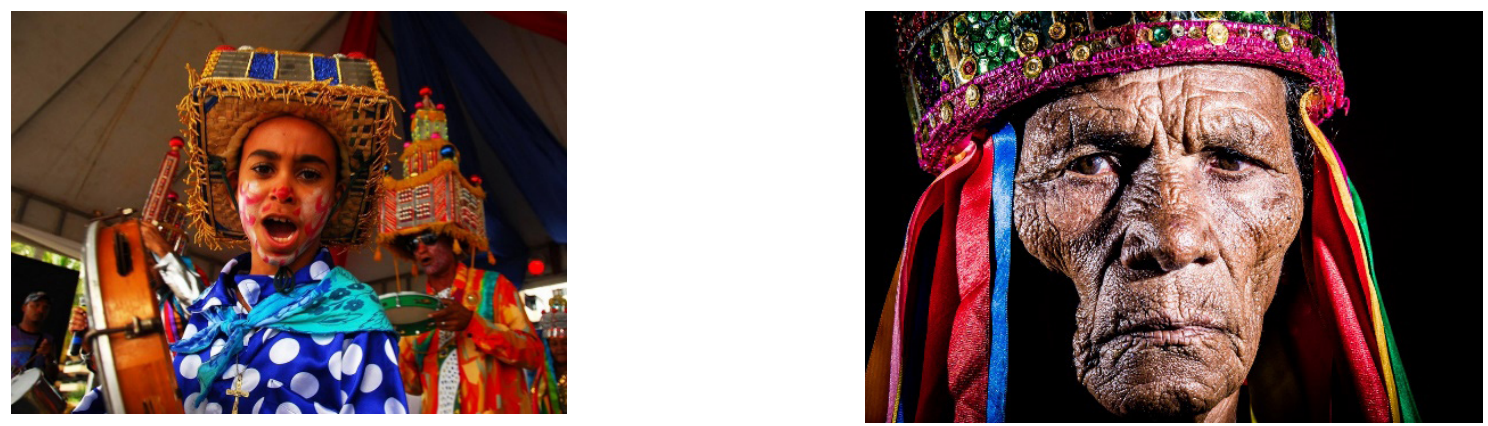

O grupo de não designers, foi formado por onze colaboradores, entre homens e mulheres, de faixa etária variada entre 17 a 85 anos de idade. 0 grupo formado por designers e designers em formação, foi realizado com a colaboração de sete alunos do curso de Design da Universidade Federal de Alagoas e um designer formado, o grupo foi composto por homens e mulheres, de faixa etária variada entre 20 a 24 anos de idade. Os procedimentos de codesign, realizados tanto com o grupo de não designers, quanto com o grupo de designers foram realizados da mesma forma, para que assim, pudesse se estabelecer um comparativo dos dados colhidos em cada grupo. O procedimento realizado será detalhado a seguir por partes, explicando como procedeu cada parte do evento, o objetivo de cada atividade, os resultados e as análises dos mesmos, descrevendo-os etapa por etapa nas etapas a seguir.

1a Etapa - Foram feitas chamadas em meio virtual, convidando o comparecimento de colaboradores para o procedimento de codesign (figura 7), neste convite os 
colaboradores não foram informados do tema que se tratava, mas souberam que iriam participar como colaboradores de um projeto. Optou-se por não avisar do que se tratava o procedimento para não alterar os dados, visto que se pretendia ter as informações do simbolismo do Guerreiro sem conhecimentos prévios, caso avisasse o tema, talvez os colaboradores buscassem informações sobre o assunto.

Figura 7 - Convite para Codesign para não designers e para designers. Fonte: Produzido pela autora, 2017.
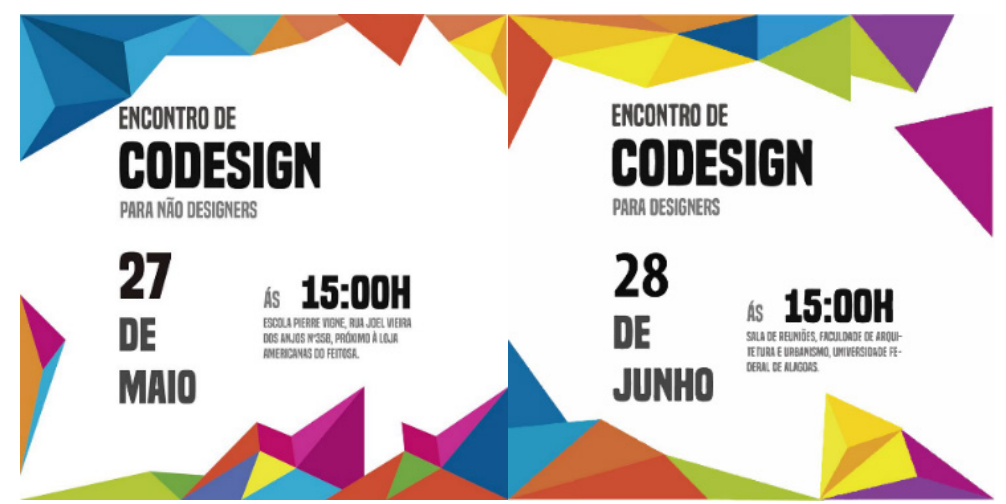

2a Etapa - Ambos os eventos ocorreram em ambientes fechados e neutros. No ambiente foram dispostas as imagens do tema Guerreiro vedadas por um pano preto (Figura 8 e 9), reveladas após um momento de relaxamento e alongamento com os colaboradores, com intuito de ficarem mais à vontade, relaxados e mais seguros em se expressar. Depois, foi feita uma brincadeira de roda, onde era apontado o "mestre" pela condutora, e os participantes tinham que imitar os movimentos de cada mestre escolhido (Vide figuras 10 e 11). Essa dinâmica tinha como objetivo relaxar os convidados, e introduzir de forma singela à prática da brincadeira, e ao espírito de coletividade presente no Guerreiro.

Figura 8 - Imagens vedadas no quadro negro. Fonte: Acervo da pesquisa, 2017. Figura 9- Imagens vedadas no quadro negro. Fonte: Acervo da pesquisa,2017.
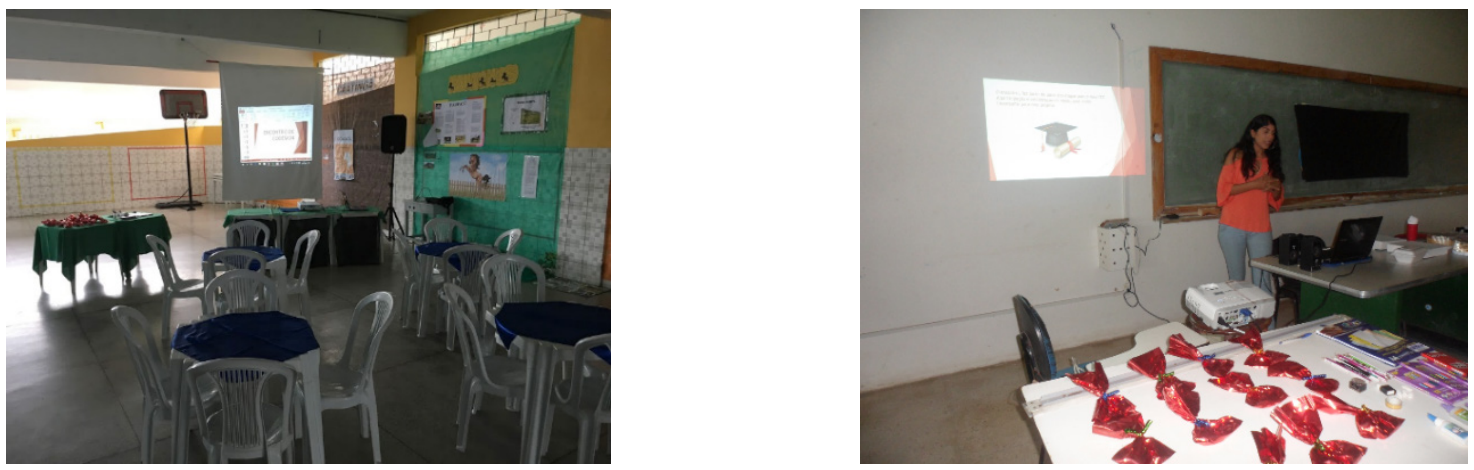

Figura 10 - Descontração não designers. Fonte: Acervo da pesquisa, 2017. Figura 11 -Descontração designers. Fonte: Acervo da pesquisa, 2017.
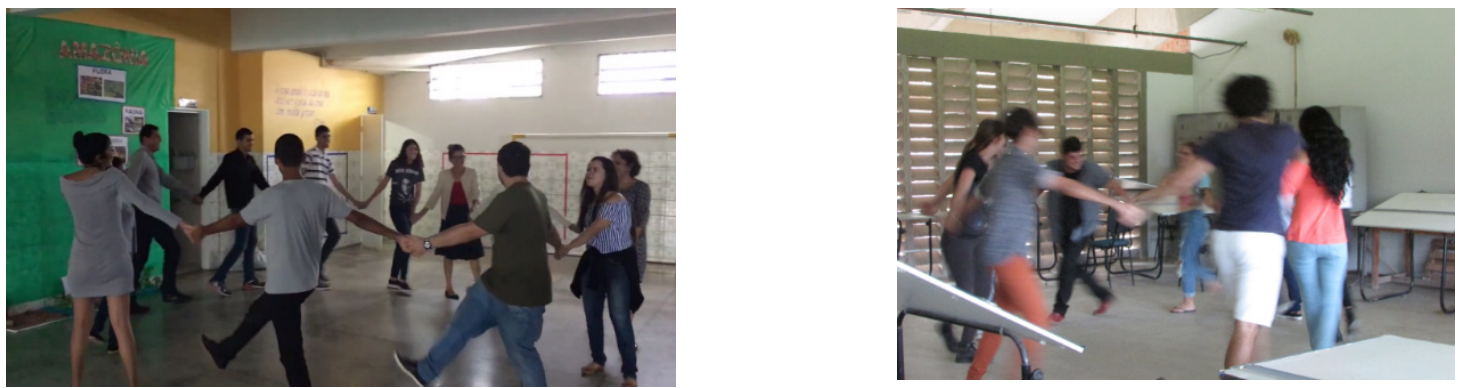
3a Etapa - Após o relaxamento, os colaboradores observaram as imagens que estavam vedadas, e cada um recebeu um papel escrito com as palavras chave mencionadas anteriormente (Vide p.7). Cada integrante teve que citar mais três palavras, desconsiderando a escrita no papel, sem poder repetir palavras já mencionadas. Após terminarem de falar as três palavras, foi explicado aos colaboradores que revelassem as palavras chave que receberam escritas no papel, foi explicado também, que o colaborador indicasse se foi mencionada a palavra chave que continha em seu papel (Figuras 12, 13, 14 e 15). Esta etapa teve como objetivo, fazer com que os colaboradores expressassem palavras representativas do Guerreiro. Então, foi elaborado um painel comparativo (Figura 16) com as palavras ditas nos dois procedimentos, sendo a primeira a palavra que eles receberam, e as outras três as palavras que os colaboradores associaram juntamente com as imagens, as palavras em comum entre os dois grupos foram indicadas e destacadas por uma cor correspondente.

Figura 12 - Observação não designers. Fonte: Acervo da pesquisa, 2017. Figura 13 -iamgens para o grupo de não designers. Fonte: Avervo da pesquisa, 2017.
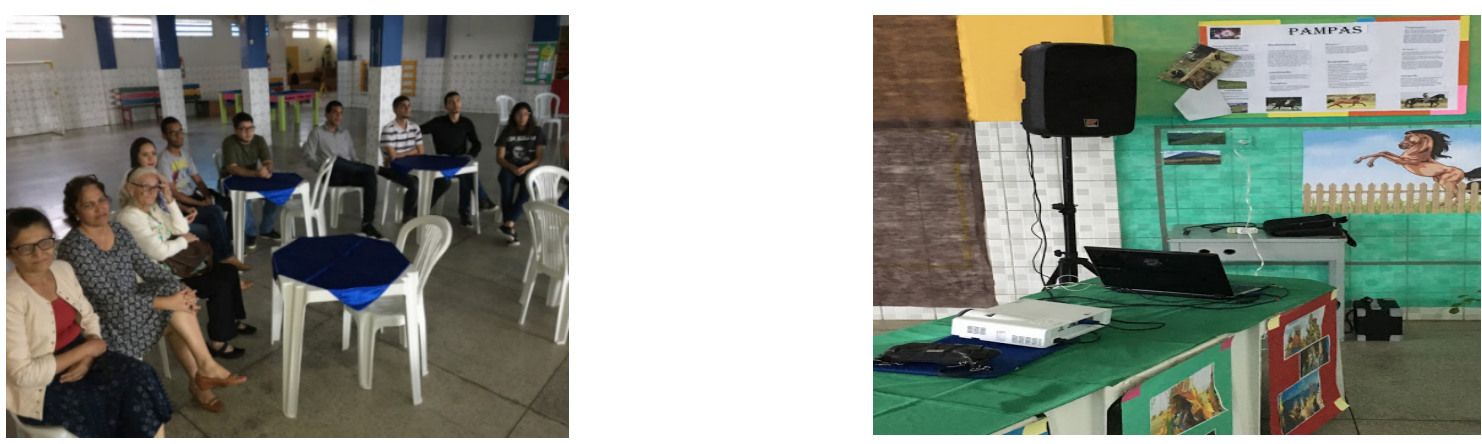

Figura 14 - Observação dos designers. Fonte: Acervo da pesquisa,2017. Figura 15 -imagens para o grupo de designers. Fonte: Acervo da pesquisa,2017.
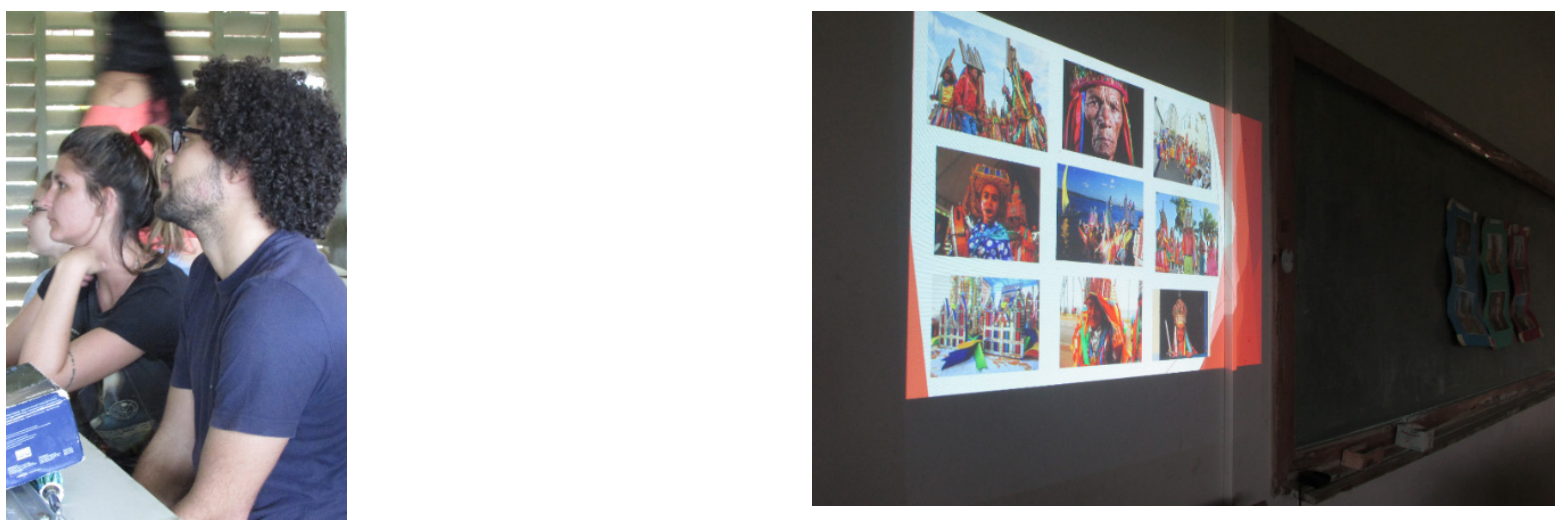
Figura 16 - Comparação dos resultados de $3^{a}$ etapa, grupo de não designers e grupo de designers. Fonte: Produzido pela autora, 2017.

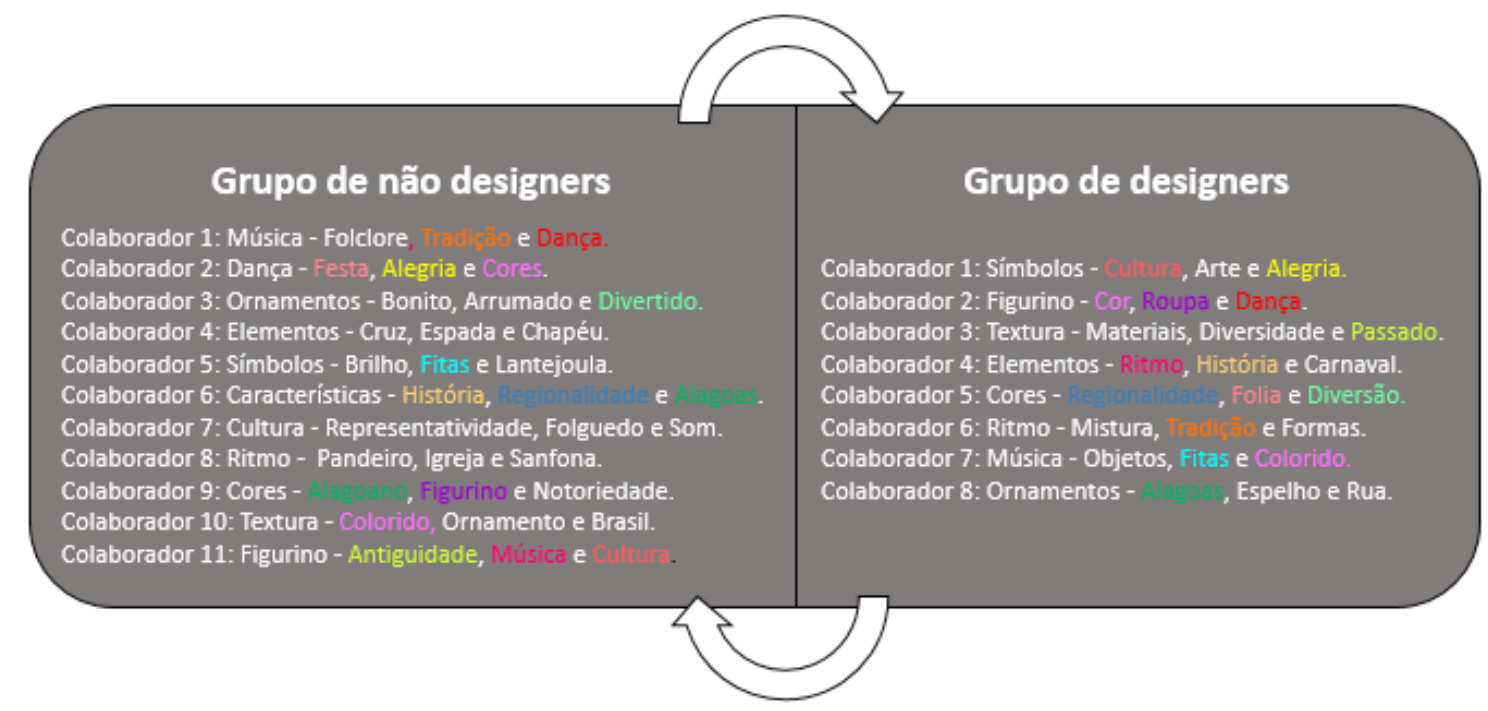

Ao observar o resultado desta atividade, é notório a repetição de algumas palavras como: fitas, regionalidade, tradição, alegria, cores, história, dança, cultura e Alagoas. Porém, nota-se também palavras de mesmo significado como: divertido e diversão com alegria, Alagoas e alagoano, figurino e roupa, colorido e cores, música e ritmo, folia e festa, passado e antiguidade.

4를 Etapa- Em seguida, os colaboradores assistiram ao vídeo sobre o Guerreiro mencionado anteriormente, e em seguida, foram convidados a expressar a experiência em relação ao vídeo (Figuras 17 e 18). Esta etapa teve como objetivo iniciar um debate da temática e fazer os convidados explorar pensamentos e compartilhar ideias que têm do folguedo.

Figura 17 - Codesign para não designers. Fonte: Acervo da pesquisa, 2017. Figura 18 -codesign para designers. Fonte: Acervo da pesquisa,2017.
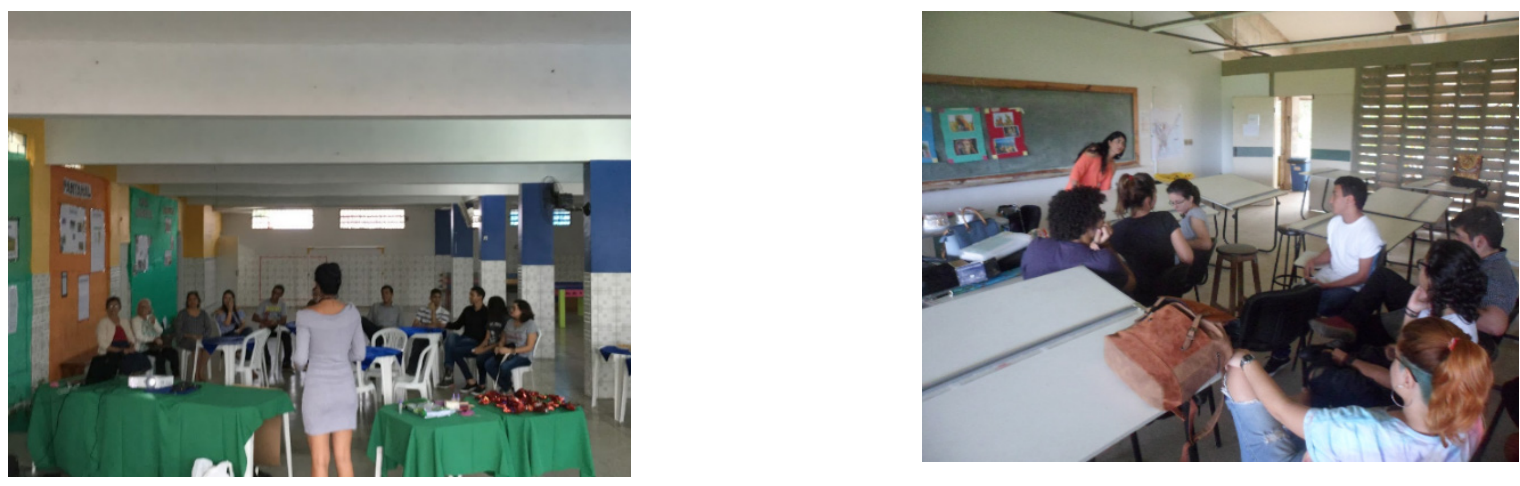

Ao analisar os depoimentos (Vide ANEXO F e ANEXO G), é possível notar o uso de algumas palavras chave representativas do guerreiro que apareceram repetidamente, durante os depoimentos sobre o Guerreiro nos dois grupos (Figura 19). 


\section{Tradição, cultura, dança, música ou harmonia ou ritmo, religião, folclore, história, espelhos, alegria, figurino, espada, chapéus, cruz, igreja, fitas, cores, pandeiro, rua ou praça e Alagoas.}

5a Etapa- Após ao debate, os colaboradores receberam o kit anteriormente mencionado, e foram instruídos à usarem a criatividade em uma representação gráfica (Figuras 20 e 21), a fim de transmitir no papel, a expressividade do Guerreiro Alagoano.

Figura 20 - Codesign para não designers. Fonte: Acervo da pesquisa,2017. Figura 21 - Codesign para designers. Fonte: Acervo da pesquisa,2017.
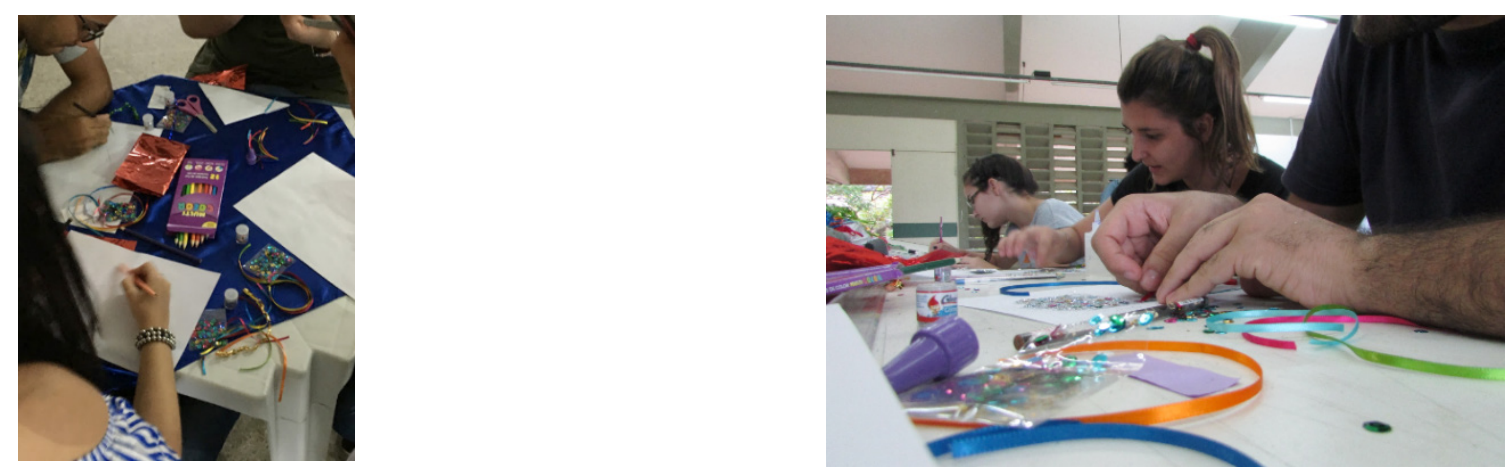

6a Etapa- Após a tarefa anterior, os colaboradores entregaram os seus respectivos trabalhos (Figuras 22 e 23), que foram utilizados para a construção de painéis que serão analisados a seguir. Após a entrega dos desenhos, foi pedido que os colaboradores escrevessem uma só palavra que resumisse o Guerreiro, os resultados foram esquematizados em duas nuvens de palavras, elaboradas para uma melhor visualização dos resultados obtidos nesta atividade (Figura 24 e 25).

Figura 22 - Codesign para não designers. Fonte: Acervo da pesquisa,2017. Figura 23 - Codesign para designers. Fonte: Acervo da pesquisa,2017.
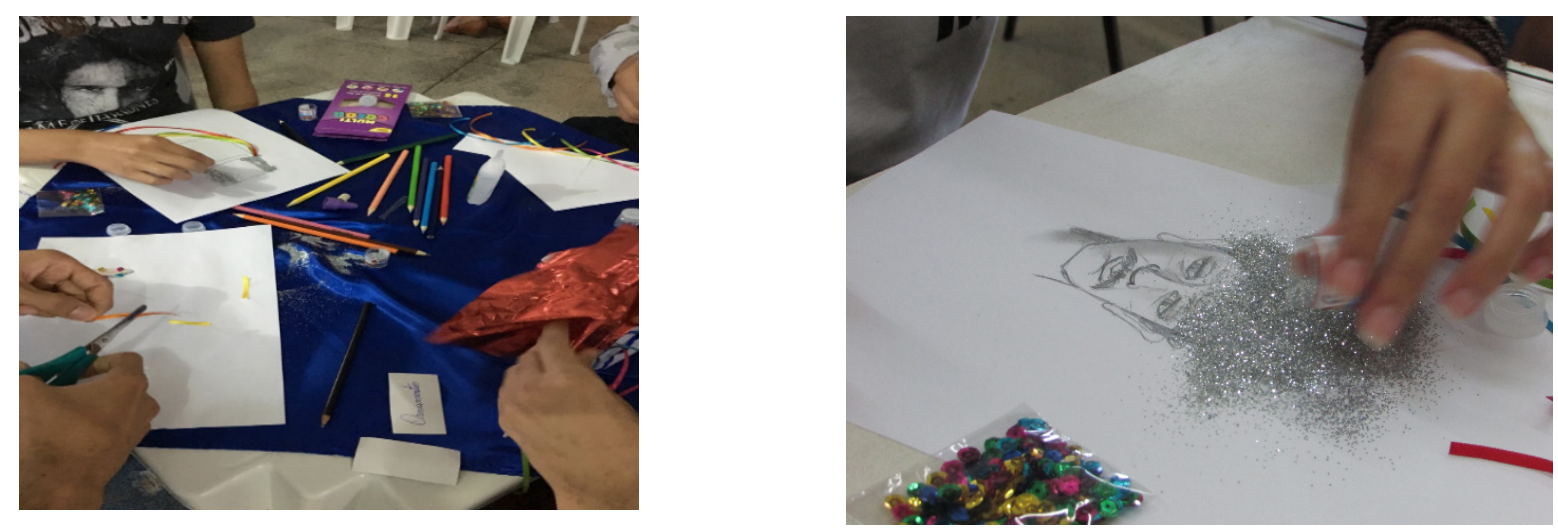
Figura 24 - Nuvem de palavras da 6⿳a etapa do Codesign para não designers. Fonte: Produzido pela autora, 2017.

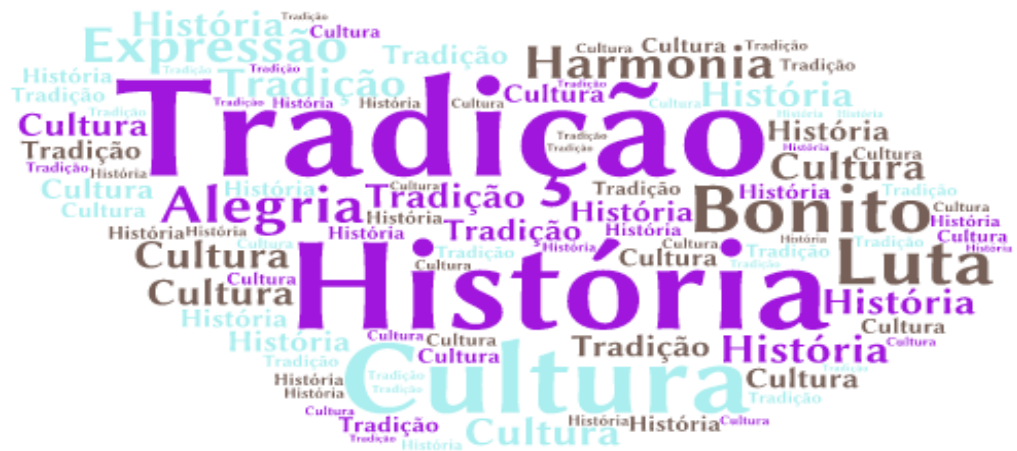

Diante desta nuvem de palavras feita das respostas do codesign para não designers, nota-se a reincidência das palavras Tradição, História e Cultura. No procedimento de codesign para designers as palavras registradas foram:

Figura 25 - Nuvem de palavras da 6 etapa do Codesign para designers. Fonte: Produzido pela autora,2017.

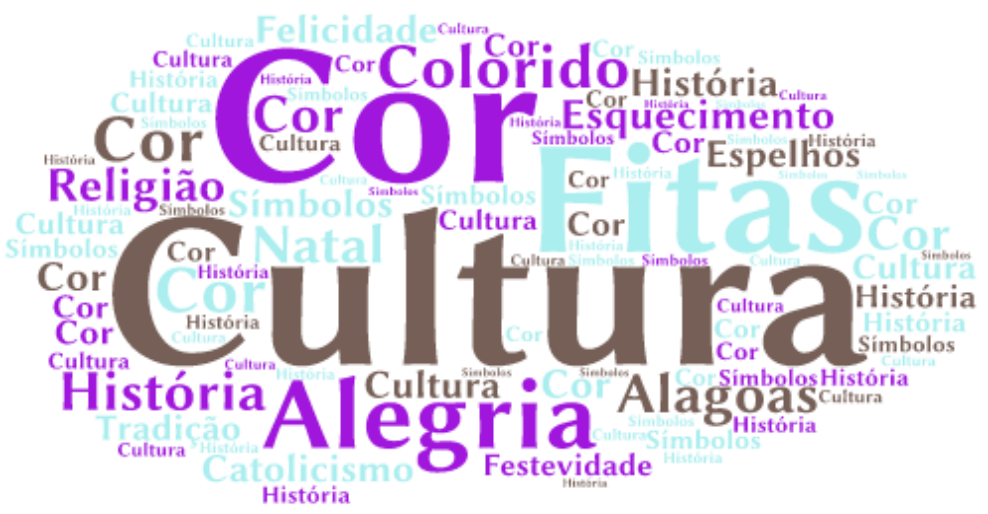

É possível constatar nesta nuvem de palavras, a recorrência das palavras Cor e Cultura. Em relação à comparação entre as palavras utilizadas pelos dois grupos de colaboradores, nota-se a reincidência de palavras como: Alegria, História, Tradição, Cor e Cultura. Nota-se também, a presença de palavras com significado negativo como luta e esquecimento.

Com base nos resultados obtidos durante a coleta de dados da pesquisa e dos dados obtidos durante as atividades dos procedimentos de codesign, segue abaixo, a lista das palavras reincidentes durante todas as atividades, e consequentemente, as mais representativas dos aspectos simbólicos do Guerreiro, na visão de um público formado de designers e de não designers, e palavras obtidas pela pesquisa deste trabalho (Figura 26). 

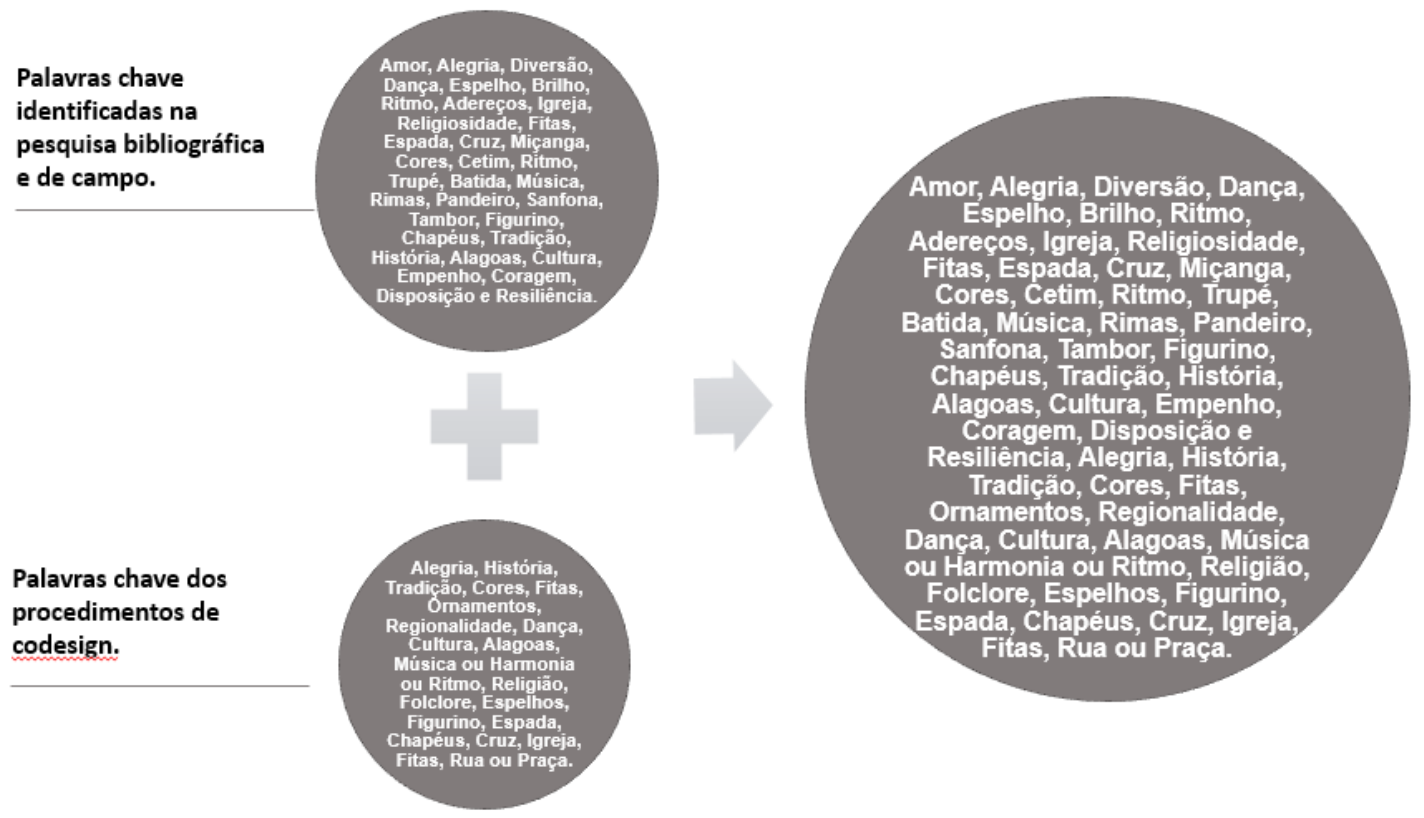

Para uma melhor análise dos desenhos, resultantes da 6a etapa dos dois procedimentos de codesign, foram elaborados painéis dos desenhos elaborados pelos colaboradores, podendo assim identificar as formas, cores, texturas e expressões mais utilizadas entre os grupos, no painel imagético Codesign para não designers (Figura 27), no painel imagético Codesign para designers (Figura 28).

Figura 27 - Painel imagético do Codesign para não designers. Fonte: Acervo da autora, 2017.

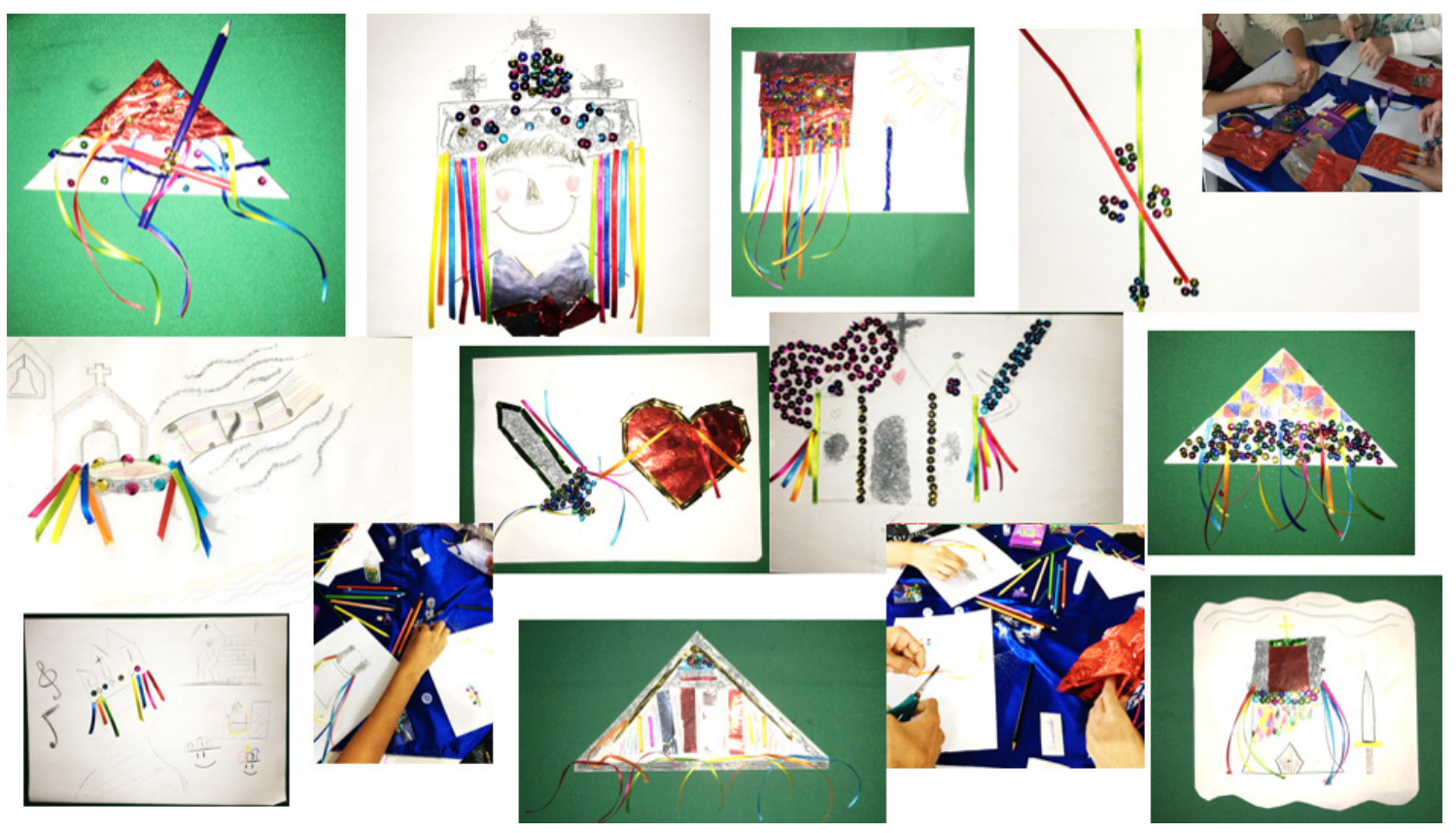

Neste painel do codesign para não designers, é possível notar a presença de formas como: chapéus de Guerreiro, pandeiro, espada, cruz, igreja, fitas. As cores utilizadas nos desenhos foram: o vermelho, azul claro e escuro, amarelo, laranja, magenta, verde claro, prateado e dourado. As texturas identificadas forma de acabamento brilhoso e espelhado com o uso do gliter e materiais laminados. Também foram representadas algumas expressões como: o coração representando amor, e notas musicais representando música, ritmo, som e um rosto feliz, demostrando alegria. 
Figura 28 - Painel imagético do Codesign para designers. Fonte: Acervo da autora, 2017.

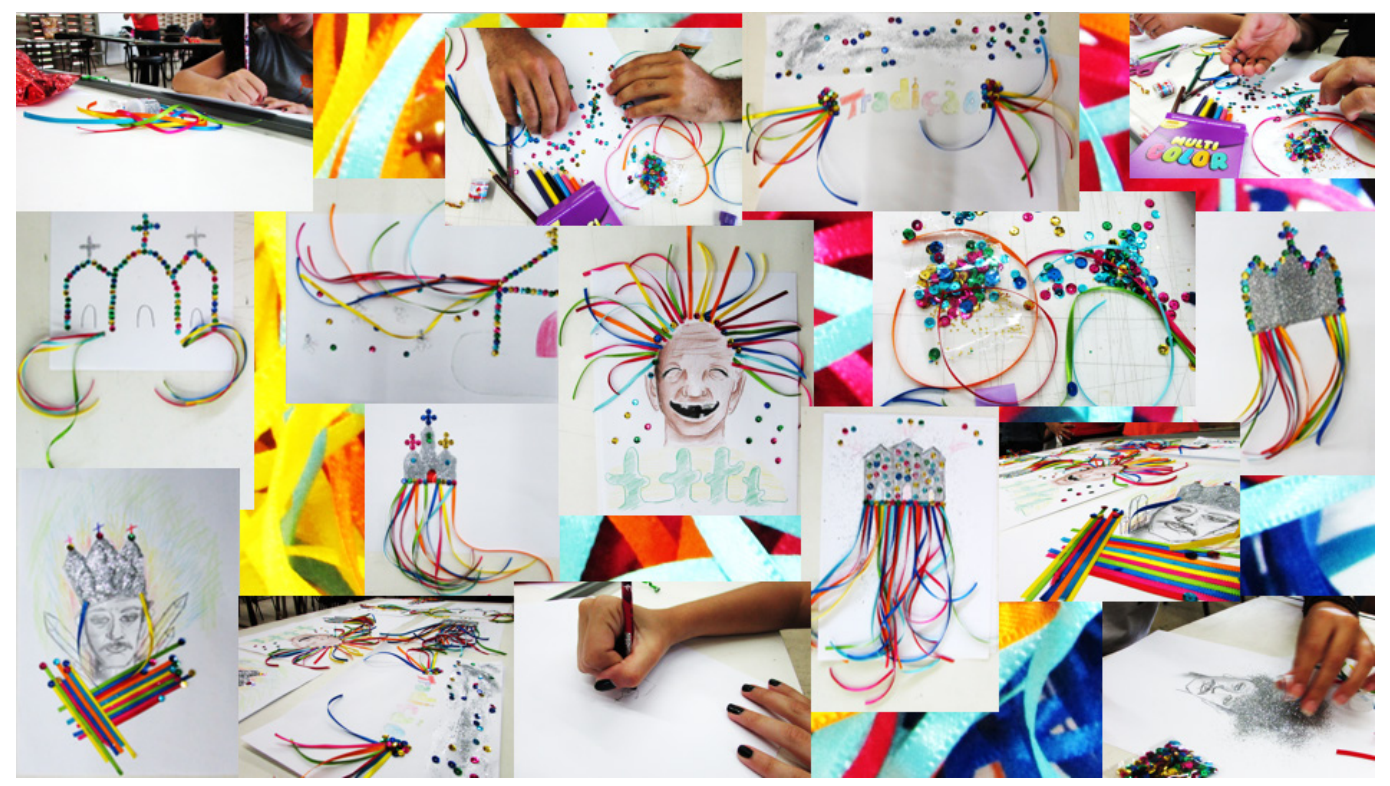

No painel de desenhos do codesign para designers, é possível notar também a presença de formas como: chapéus de Guerreiro, espada, igreja, fitas. As cores utilizadas nos desenhos foram: o azul claro e escuro, verde claro, amarelo, laranja, vermelho magenta, prateado e dourado. Como no painel anterior, as texturas brilhosas e espelhadas foram muito utilizadas. As expressões utilizadas foram: um rosto feliz, demostrando alegria, a utilização da palavra tradição como representação, pessoas dançando em frente à igreja, demostrando ser uma festa religiosa e um personagem do guerreiro com a feição séria, no meio de fitas e espadas utilizando o chapéu do Guerreiro.

A partir dos painéis obtidos nos procedimentos, para uma melhor visualização dos resultados, foi elaborada uma paleta de cores (Figura 29) e esquematização da conclusão dos resultados dos elementos simbólicos do guerreiro Alagoano mais reincidentes durante a pesquisa, eles serão descritos nos tópicos seguir (Figura 30).

Figura 29 - Paleta de cores retiradas dos painéis dos procedimentos de codesign. Fonte: Acervo da autora, 2017.

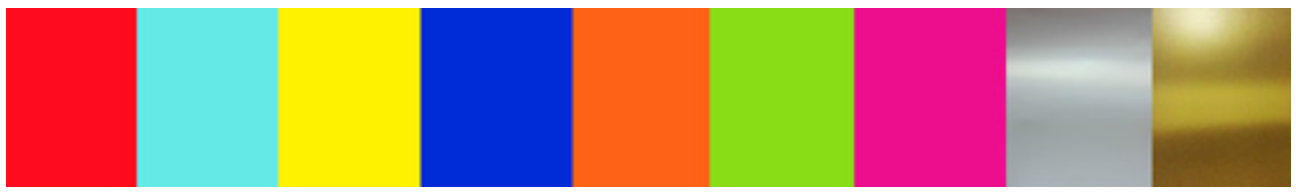

Figura 30 - Nuvem de palavras da 6a etapa do Codesign para designers. Fonte: Produzido pela autora,2017.

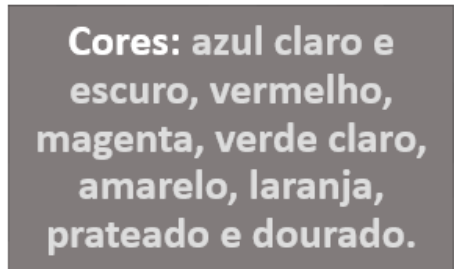

Texturas: de

acabamento brilhosos, reluzentes, acetinadas

e espelhadas.
Formas: chapéus do

Guerreiro, espada,

cruz, igreja, fitas e

pandeiro.

Expressão: amor,

alegria, religiosidade,

tradição, musicalidade 


\section{REFERÊNCIAS}

AGUINAGA, Karyn Ferreira Souza. A proteção do patrimônio cultural imaterial e os conhecimentos tradicionais. In: XV Congresso Nacional do Conpedi. 2006. Disponível em:<http://www.conpedi.org>. Acesso em: 14 jul. 2007.

BRANDÃO, Théo. 0 reisado alagoano. UFAL, 1953.

DA SILVA, Cláudio Antônio Santos. A Dança do Guerreiro Alagoano e seus Entremeios Multirreferenciais. I Encontro Nacional de Etnocenologia. Bahia, Salvador: UFBA, 2016.

DE LIMA, Rossini Tavares. A ciência do folclore. Martins Fontes, 2003.

FONTANA, Isabela Mantovani; HEEMANN, Adriano; FERREIRA, Marcelo Gitirana Gomes. Fatores críticos de sucesso para a colaboração no design de sistemas produto- serviço. Design e Tecnologia, 2012.

IPHAN, Mapeamento do patrimônio imaterial cultural de Alagoas. Disponível em: 2017.

<http://portal.iphan.gov.br/pagina/detalhes/959/> Acesso em 04 de Feverereiro de

KRUCKEN, Lia; MOL, lara. ABORDAGENS PARA COCRIAC̣ÃO NO ENSINO DO DESIGN: REFLEXÕES SOBRE INICIATIVAS NO CONTEXTO DA GRADUAÇÃO E DA PÓS

GRADUAÇÃO. Blucher Design Proceedings, 2014.

LÖBACH, Bernd. Design industrial. São Paulo: Edgard Blücher, 2001.

SCOLARI, Sergio Henrique Prado. Design e emoção: um modelo de círculos de referências de emoções em produtos. São Paulo: Universidade Estadual Paulista. Faculdade de Arquitetura, Artes e Comunicação, 2008.

SEDEC, Secretária do Estado do Desenvolvimento Econômico, Energia e Logística de Alagoas; SEBRAE/AL, Serviço de Apoio às Micro e Pequenas Empresas de Alagoas. Iconografia Alagoana, 2011.

SescTV. Publicado em 01 nov. 2013. Disponível em:<https://www.youtube.com/ watch?v=WVgo_h0b76Y>. Acesso em: 05 mai. 2017. 